\title{
Hepatitis B vaccination status and Needle-stick and Sharps-related Injuries among medical school students in Nepal: a cross-sectional study
}

\author{
Suraj Bhattarai ${ }^{1,2^{*}}$, Smriti KC $^{3}$, Pranil MS Pradhan ${ }^{4}$, Sami Lama ${ }^{5}$ and Suman Rijal ${ }^{6}$
}

\begin{abstract}
Background: Hepatitis B is a dreadful infectious disease and a major global health problem. Health-care workers including clinical students are more vulnerable to such infections and non-sterile occupational exposures as their daily activities are closely related to patient's blood and body fluids.

Methods: A descriptive cross sectional study was conducted at B.P. Koirala Institute of Health Sciences (BPKIHS), Dharan, Nepal from July till October 2012. All medical, dental and nursing students were surveyed for their Hepatitis $B$ vaccination status and only those students in clinical rotations were surveyed for the prevalence and pattern of Needle-stick and Sharps-related Injuries (NSSIs) using a pre-tested, semi-structured, self-administered questionnaire. Descriptive and inferential statistics was used to analyze the data.

Results: Majority (86.5\%) of students were vaccinated against Hepatitis B of which $83.7 \%$ had completed full doses. Among non-vaccinated students, $43.2 \%$ reported the main reason for non-vaccination as lack of vaccination programs. Out of 210 respondents from clinical rotations, 90 students (42.8\%) reported at least one injury. Among those injured, two students reported exposure to Human immunodeficiency virus (HIV) positive cases and four to Hepatitis B virus (HBV) positive cases. Most of the injuries (44\%) occurred during Internal Medicine rotation and the most common sharp involved (56.3\%) was Hypodermic needle. Most injuries (35.6\%) occurred while manipulating needle into patients. Following exposure, only $11.4 \%$ took Post exposure prophylaxis and $19.54 \%$ went for a Post-exposure serology test.

Conclusions: Needle-stick and Sharps-related Injuries occur frequently among health care workers including trainee students keeping them at high risk for acquiring dreadful infections like HBV, HCV and HIV. They need to be protected from unwarranted hazards by adopting routine Hepatitis B vaccination programs and by reinforcing education regarding universal precautions.
\end{abstract}

Keywords: Hepatitis B vaccination, Needle-stick and Sharps-related Injuries, Universal precautions

\section{Background}

Hepatitis B is a dreadful infectious disease and a major global health problem. It can be asymptomatic, symptomatic or potentially fatal and can take the form of an acute to chronic liver disease. Nearly 2 billion people have been estimated to be infected with HBV worldwide and more than 240 million people have chronic liver infections. About 600,000 people die every year due to consequences of viral hepatitis B, either acute or chronic [1,2].

\footnotetext{
* Correspondence: surajbpkihs2012@gmail.com

1 B.P. Koirala Institute of Health Sciences (BPKIHS), Dharan, Nepal

${ }^{2}$ Ishan Children and Maternity Hospital, Kathmandu, Nepal

Full list of author information is available at the end of the article
}

Hepatitis B virus is spread by contact with infected blood or body fluids - from mother to child, child to child, parenteral routes, transfusion of blood or blood products and unprotected sexual intercourse. [2] HBV can also remain on any surface it comes into contact with for about a week for e.g. on table tops, blades, blood stains without losing its infectivity [1].

Hepatitis $B$ is a vaccine preventable infection and the vaccine has been available in the world since 1982. The $\mathrm{HBV}$ vaccine is $95 \%$ effective in preventing infection and its chronic consequences. It is the first vaccine against a major human cancer i.e. Hepatocellular Carcinoma [1]. 
World Health Organization (WHO) has recommended vaccination for all infants, all children and adolescents younger than 18 years age and for all high-risk groups which include people with high-risk sexual behavior, partners and household contacts of infected ones, injecting drug users, people who frequently require blood or blood products, recipients of solid organ transplantation, people at occupational risks of hepatitis B virus infection, and travelers to the countries with high rates of hepatitis B infection [1].

In Nepal, about 315,000 people are estimated to be living with chronic hepatitis B infection [3]. However; the exact data of acute infections are unavailable in the national directory. Although National Immunization Program introduced Hepatitis B vaccination in 2003, an accurate immunization status of the population is also still unknown. So far, it is being administered as a component of Pentavalent injection (DPT-HepB-Hib) to the infants only [4]. The government doesn't have any program to vaccinate at-risk population such as Health-Care Workers (HCWs). The health institutions have also failed to ensure protection of their employees and trainees.

In-service activities of a HCW are closely related to patient's blood or body fluids. They are likely to sustain non-sterile exposures either in the form of needle-sticks, sharps-related injuries or splashes of body fluids to eyes and mucus membranes. If one sustains a needle stick and the source (patient) is an infected one, the risk of transmission of HIV, HBV and HCV per exposure is $0.3 \%, 37-62 \%$ and $1.8 \%$ per exposure respectively [5]. It is estimated that Sharps-related injuries cause about 66,000 HBV, $16000 \mathrm{HCV}$ and 200-5000 HIV infections each year among HCWs globally [6].

The present study aims at exploring Hepatitis B vaccination coverage among medical, dental and nursing students of a Medical school in Nepal, the main reasons for non-vaccination and the association between vaccination status and socio-demographic variables. It also aims at studying the prevalence and pattern of NSSIs among trainee students.

\section{Methods}

It was a cross-sectional study conducted in BP Koirala Institute of Health Sciences, Dharan, Nepal from July 2012 to October 2012. BPKIHS is a 700 bedded multispecialty, teaching and referral hospital located in Eastern Development Region of Nepal. Dharan is a major city of Eastern Nepal and represents the geographical transition between the long ranges of mountains in the North and the extensive plains of Terai belt in the South. The city has both cultural and socioeconomic diversity. The local people rely on BPKIHS for their health needs. According to national surveys, the population of this region has relatively higher prevalence of infectious diseases like HBV, HCV and HIV as compared to the other parts of the country.

In BPKIHS, medical and dental students start handson training during internship rotations whereas nursing students start it right from the beginning of course. Our study was conducted among the students who represented the batches from 2006 to 2012.

\section{Study population and sample size Hepatitis $B$ vaccination status}

All medical, dental and nursing students of BPKIHS ranging from Batch 2006 to Batch 2011 and willing to participate in the study were included in our study. There were overall six batches of medical and dental students (Batch 2006-2011), four batches of B. Sc. Nursing students (Batch 2008-2011) and three batches of Certificate Nursing students (Batch 2009-2011). The number of students enrolled each year in each batch of medical, dental, B.Sc. Nursing and Certificate Nursing faculty is $100,40,20$ and 40 respectively. Those students who were absent during two-week period of data collection were excluded from the study.

\section{Prevalence of Needle-stick and Sharps-related Injuries (NSSIs)}

All medical/dental interns of 2011/2012 academic session, who had completed 12 months of compulsory rotatory internship by August 2012, and all nursing students (both B.Sc. and Certificate Nursing students from first year through final year) were included. Medical and dental students start hands-on training usually during internship whereas nursing students do it from the beginning of their course. Interns and the nurses absent at the time of data collection were also excluded. The sample size was calculated on the basis of a similar study carried out in School of Population Health, University of Melbourne where overall prevalence of Needle-stick injury among Healthcare workers was 63\% [7]. We calculated the sample size of 226 at $95 \%$ confidence and $10 \%$ allowable error and considering $20 \%$ of non response, we calculated our final sample size to be 270 .

Simple random sampling method was adopted while taking samples.

\section{Research instrument}

A semi-structured questionnaire was developed including questions on hepatitis $B$ vaccination status and NSSIs. The questionnaire was categorized into 4 sections: section 1- socio-demographic profile, section 2Hepatitis B vaccination details, section 3- reasons for non-vaccination, section 4- NSSIs details. Only the interns and nursing students were requested to fill up section 4 . 
Sections 4 had different sub-headings: the prevalence of NSSIs, types of instruments involved in injury such as hypodermic needle, scalpel or a suturing needle; procedures involved such as drawing venous or arterial blood, suturing wounds, conducting labor, dental extraction; circumstances of injury such as while recapping used needle, manipulating needle back and forth into patient, administering intravenous or intramuscular medication, accidental injury by others, cleaning up and disposal; and causes of injury such as stress at work, understaffing, not following universal precaution, uncooperative patient.

The content validity of the research instruments was ensured after reviewing the literature and consultation with research guides, advisors and experts on the subject. Based on their opinions, modification was done accordingly.

The questionnaire was pretested by taking $10 \%$ of the sample. Questionnaires were distributed in the classrooms. A detailed briefing regarding questions and objectives of study was made prior to data collection.

\section{Definition of the variables $H B V$ vaccination status}

Students are either vaccinated or not vaccinated. Those who received less than 3 doses of $\mathrm{HBV}$ vaccination by the time of data collection were categorized as partially vaccinated ones.

\section{Needle-stick and Sharps-related Injury (NSSI)}

An injury with a needle, scalpel blade, catheter stylet or other pointed object which was used for any invasive procedure with a patient and contaminated with blood or body fluids.

These two were considered as dependant variables whereas faculty, batch, age, sex and nationality of participants as independent variables. Faculty was divided into medical (MBBS), dental (BDS) and Nursing (both B.Sc. and Certificate). Batch varied from 2006 to 2011 including interns of 2011/2012 session. Majority of students in this institution were Nepalese followed by Indians.

\section{Data analysis}

The coded data was entered in Microsoft EXCEL 2007 and transformed in SPSS (SPSS Inc. Released 2007, SPSS for Windows Version 16.0 Chicago, SPSS Inc.). Both descriptive statistics (frequency, median, mean, interquartile range, standard deviation and percentage) and inferential statistics were used to represent the data. Chi-square test was applied in bi-variate analysis for association among categorical variables; the probability of significance was set at $5 \%$.

\section{Ethical consideration}

Our research team obtained written permission from Institution Ethical Review Board (IERB) of BPKIHS to carry out the study. The objectives of study were explained to the participants and a written consent was obtained from each respondent prior to data collection. The participation was entirely voluntary and confidentiality of the responses was duly maintained.

\section{Results}

Out of 930 students we approached to assess HBV vaccination status, 622 returned the answered questionnaires which gave the response rate of $66.9 \%$. Among them, 20 responses were incomplete. Therefore, only 602 became valid for analysis. Likewise, the response rate for the details of Needle stick and sharps related injury was 73.3\% (210 out of 270 questionnaires distributed).

\section{Hepatitis B vaccination status}

\section{Socio-demographic characteristics}

Among 602 respondents, 55.1\% were male and 44.9\% were female. Majority of them (62.9\%) were $\leq 22$ yrs age and the mean age \pm SD was $21.6 \pm 2.215$ years. More than half of the respondents were medical students (56.5\%). Dental, BSc. Nursing and Certificate nursing students were $16 \%$, $12.1 \%$ and $15.4 \%$ respectively (Table 1 ).

\section{Vaccination status of the students and reasons for non- vaccination}

A majority (86.50\%) of respondents were vaccinated against hepatitis B leaving $13.5 \%$ non-vaccinated. The coverage was $85.3 \%$ among medical, $80.2 \%$ among dental and $92.7 \%$ among nursing students (BSc. and CN combined). Among those vaccinated, 83.7\% (436/521) were

Table 1 Socio-demographic characteristics of students in BPKIHS ( $n=602)$

\begin{tabular}{llll}
\hline Description & Category & Frequency & Percentage \\
\hline Faculty & MBBS & 340 & 56.5 \\
& BDS & 96 & 16.0 \\
& B.Sc. Nursing & 73 & 12.1 \\
& Certificate. Nursing & 93 & 15.4 \\
Batch & 2006 & 44 & 7.3 \\
& 2007 & 42 & 7.0 \\
& 2008 & 103 & 17.1 \\
& 2009 & 136 & 22.6 \\
& 2010 & 130 & 21.6 \\
Sex & 2011 & 147 & 24.4 \\
& Male & 332 & 55.1 \\
& Female & 270 & 44.9 \\
& $\leq 22$ yrs & 379 & 63.0 \\
Nationality & N22 yrs & 223 & 37.0 \\
& Nepali & 544 & 90.4 \\
\hline
\end{tabular}


fully immunized, i.e. they received 3 or more doses of vaccination, whereas $16.3 \%$ (85/521) were only partially immunized. When we asked about the reasons for nonvaccination, $43.2 \%$ of the non-vaccinated group stated there was lack of vaccination programs and $21 \%$ told that they never thought about it.

\section{Needle-stick and Sharps-related Injuries (NSSIs) Prevalence of injury}

Out of 210 students in clinical rotations, 90 (42.8\%) had experienced at least one injury. Among those 90, 63 (70\%) were nursing students (B.Sc. and Certificate Nursing), 18 (20\%) were medical interns and 9 (10\%) were dental interns. In a different revelation, 33 students (15.7\%) had also experienced the splashes of patient's body fluids. Such splashes occurred with patient's blood in $24(72.8 \%)$, amniotic fluid in $2(6.0 \%)$ and other types of fluid in 7 students (21.2\%).

Among those 90 students who had NSSI, two students reported injury or exposure to HIV positive patient (2.2\%) and four students to HBV positive patient (4.4\%). More than half of the remaining students were unsure about the serology status of source patient.

Likewise, 39 sustained the injury only once, 33 sustained it twice, 12 sustained it thrice and 3 sustained it even four times till the date of survey. Remaining 3 students did not disclose the frequency of injuries. A detail of their first incident was utilized to know the patterns of Needle-stick and Sharps-related injuries in the hospital.

\section{Type of instrument involved in injury}

More than half $(57.8 \%)$ of those 90 students sustained injury with Hypodermic/Hollow bore needle whereas $27.8 \%$ sustained injury with Suturing needle (Table 2).

\section{Place and procedure related to injury}

A majority (41.1\%) of injuries occurred in Internal Medicine followed by Obstetrics-Gynecology \& Labor wards (23.3\%). The most common procedure that inflicted injury was while drawing patient's venous blood (31.1\%) followed by while conducting delivery in the labor room (17.8\%) (Table 3).

The most common circumstance leading to injury was while manipulating needle back and forth into the

Table 2 Type of Instrument involved in injury $(n=90)$

\begin{tabular}{llll}
\hline Description & Category & Frequency & Percentage \\
\hline Types of needle/sharps & Hypodermic needle & 52 & 57.8 \\
& Suturing needle & 25 & 27.8 \\
& Scalpel/blade & 3 & 3.3 \\
& IV catheter & 3 & 3.3 \\
& Wire/Force/Retractor & 5 & 5.6 \\
& Dental sharp & 2 & 2.2 \\
\hline
\end{tabular}

Table 3 Details of the first incident of injury $(n=90)$

\begin{tabular}{llll}
\hline Description & Category & Frequency & Percentage \\
\hline Department in & Internal Medicine ward & 37 & 41.1 \\
which injury & Surgery ward & 12 & 13.3 \\
occurred & ObGyn ward and Labor room & 21 & 23.3 \\
& Pediatrics ward & 2 & 2.2 \\
& Emergency Department & 2 & 2.2 \\
& Orthopedics ward & 3 & 3.3 \\
& Dental department & 9 & 10 \\
Procedure & Laboratory & 4 & 4.4 \\
involved during & Drawing venous blood & 28 & 31.1 \\
& for lab & & \\
& Opening Intravenous access & 11 & 12.2 \\
& Suturing wounds & 4 & 4.4 \\
& Conducting labor & 16 & 17.8 \\
& Drawing arterial blood & 3 & 3.3 \\
& (ABG) & & \\
& Measuring blood sugar & 4 & 4.4 \\
& level with Glucometer & & \\
& Others & 12 & 13.4 \\
& Dental extraction & 8 & 9.0 \\
& Lab works-Hematology & 4 & 4.4 \\
\hline
\end{tabular}

patient for venous or arterial access (35.6\%) followed by while administering medication thru intravenous or intramuscular route (24.4\%). Likewise, common causes of injury as cited by the respondents were uncooperative patient (33.3\%) and stress during work (16.7\%). Some $16.7 \%$ stated that the injury happened while carrying out the particular procedure for the first time (Table 4).

\section{Tendency of seeking post-exposure prophylaxis (PEP) after an exposure}

There was a low tendency of consultation and reporting to the concerned authority after getting exposed to patient's blood through injury. Less than a half $(41.4 \%)$ of respondents consulted with their seniors. The tendency of seeking PEP was also found to be very low. Only 10 students (11.1\%) revealed that they took PEP either in the form of Tetanus toxoid vaccination or oral antibiotics. Two students who were exposed to HIV positive patients had started taking anti-retroviral prophylaxis. Likewise, only one-fifth of the exposed ones (18 out of 90) went for a post-exposure serological test (HIV, Hep $\mathrm{B}$ or HCV). To find out the result of such test and its sequel was beyond the scope of our study.

Chi-square analysis of different variables has been shown in Tables 5 and 6 . Hepatitis B vaccination status of the respondents was significantly associated with faculty $(\mathrm{p}=0.024)$ and gender $(\mathrm{p}=0.007)$ (Table 5). 
Table 4 Circumstances and causes of injuries and exposures $(\mathbf{n}=90)$

\begin{tabular}{|c|c|c|c|}
\hline Description & Category & Frequency & Percentage \\
\hline \multirow{12}{*}{$\begin{array}{l}\text { Most common } \\
\text { circumstance } \\
\text { leading to injury }\end{array}$} & $\begin{array}{l}\text { While recapping used } \\
\text { needle }\end{array}$ & 17 & 18.9 \\
\hline & $\begin{array}{l}\text { While cleaning up the } \\
\text { procedure area and } \\
\text { disposal of instruments }\end{array}$ & 8 & 8.9 \\
\hline & While administering & 22 & 24.4 \\
\hline & $\begin{array}{l}\text { medications thru IV/IM } \\
\text { route }\end{array}$ & & \\
\hline & $\begin{array}{l}\text { While manipulating needle } \\
\text { back and forth in the }\end{array}$ & 32 & 35.6 \\
\hline & patient for venous/arterial & & \\
\hline & Access & & \\
\hline & Collision with needles or & 3 & 3.3 \\
\hline & $\begin{array}{l}\text { sharps left in improper } \\
\text { places }\end{array}$ & & \\
\hline & Accidentally injured by others & 2 & 2.2 \\
\hline & While assisting operation & 1 & 1.1 \\
\hline & Other circumstances & 5 & 5.6 \\
\hline \multirow{8}{*}{$\begin{array}{l}\text { Most common } \\
\text { cause of injury }\end{array}$} & Stress at work & 15 & 16.7 \\
\hline & $\begin{array}{l}\text { Particular procedure for } \\
\text { the first time }\end{array}$ & 15 & 16.7 \\
\hline & $\begin{array}{l}\text { Over confidence for } \\
\text { particular procedure }\end{array}$ & 5 & 5.6 \\
\hline & $\begin{array}{l}\text { Not using safety } \\
\text { precautions }\end{array}$ & 11 & 12.2 \\
\hline & Uncooperative patient & 30 & 33.3 \\
\hline & Understaffed situation & 4 & 4.4 \\
\hline & $\begin{array}{l}\text { Carelessness/ } \\
\text { Inattentiveness }\end{array}$ & 4 & 4.4 \\
\hline & Others & 6 & 6.7 \\
\hline
\end{tabular}

Needle stick and sharps-related injury was significantly associated with faculty $(\mathrm{p}=0.042)$, age $(\mathrm{p}<0.001)$ and gender $(\mathrm{p}<0.001)$ (Table 6).

\section{Discussion}

Hepatitis B vaccination coverage among medical school students in our study was $86.50 \%$ which is comparable to a study carried out in Malaysia (85.5\%) [7]. The vaccination rates in two different medical schools of Pakistan were $57 \%$ and $42 \%$ respectively $[8,9]$. A previous study of similar kind but conducted among Health care workers in Nepal found the vaccination rate to be $60 \%$ [10]. In this light, our finding somehow indicates the rising awareness on occupational health, hazards and preventive measures.

In our study, a majority of the students from each faculty (medical, dental and nursing) were found have
Table 5 Association of Hepatitis B vaccination status with the socio demographic variables $(n=602)$

\begin{tabular}{lllll}
\hline Characteristics & Category & \multicolumn{2}{l}{$\begin{array}{l}\text { Vaccination against } \\
\text { Hepatitis B }\end{array}$} & p-value \\
\cline { 3 - 4 } & & Yes & No & \\
\hline Faculty & MBBS & $290(85.3)$ & $50(14.7)$ & \\
& BDS & $77(80.2)$ & $19(19.8)$ & $\mathbf{0 . 0 2 4}$ \\
& B.Sc. Nursing & $67(91.8)$ & $6(8.2)$ & \\
& C. Nursing & $87(93.5)$ & $6(6.5)$ & \\
Age Group (years) & $\leq 22$ yrs & $328(86.5)$ & $51(13.5)$ & 0.999 \\
& $>22$ yrs & $193(86.5)$ & $30(13.5)$ & \\
Sex & Male & $276(83.1)$ & $56(16.9)$ & $\mathbf{0 . 0 0 7}$ \\
& Female & $245(90.7)$ & $25(9.3)$ & \\
Nationality & Nepalese & $472(86.8)$ & $72(13.2)$ & 0.628 \\
& Indian & $49(84.5)$ & $9(15.5)$ & \\
\hline
\end{tabular}

vaccination against Hepatitis B. Almost all students had had this privilege in Canada [11]. In contrast, surprisingly only $1.9 \%$ of nursing students had had vaccination in a medical school of Orissa, India [12].

Lack of effective vaccination programs in our country was the main reason cited for non-vaccination (43.2\%). In Pakistan, the reason was high cost of vaccination (44.7\%) and a false belief among students that they were not even at risk (33.7\%) [9]. Asif $\mathrm{M}$ et al., in another study, reported that students did not receive vaccination because there was a lack of motivation among peers $(29.2 \%)$ and some even did not feel the need of it (24.8\%) [8].

The prevalence of NSSI among trainee students in our institute was $42.8 \%$. A previous study carried out in Nepal but among health care workers reported it to be $74 \%$ [10]. However, it cannot be stated that the prevalence has really reduced. Our study targeted the trainee students who might have failed to recall and report the

Table 6 Association of NSSIs with socio demographic variables $(n=210)$

\begin{tabular}{lllll}
\hline Characteristics & Category & NSSls & & p-value \\
\cline { 3 - 4 } & & Present & Absent & \\
\hline Faculty & MBBS & $18(64.3)$ & $10(35.7)$ & \\
& BDS & $9(56.3)$ & $7(43.8)$ & $\mathbf{0 . 0 4 2}$ \\
& B.Sc. Nursing & $29(39.7)$ & $44(60.3)$ & \\
& C. Nursing & $34(36.6)$ & $59(63.4)$ & \\
Age Group (years) & $\leq 22$ & $51(34.0)$ & $99(66.0)$ & $<0.001$ \\
& $>22$ & $39(65.0)$ & $21(35)$. & \\
Sex & Male & $24(61.5)$ & $15(38.5)$ & \\
& Female & $66(38.6)$ & $105(61.4)$ & $<\mathbf{0 . 0 0 1}$ \\
Nationality & Nepalese & $87(42.4)$ & $118(57.6)$ & 0.653 \\
& Indian & $3(60.0)$ & $2(40.0)$ & \\
\hline
\end{tabular}


injuries or simply hesitated to reveal it for personal reasons.

Our finding is in accord with that in Mongolia where the NSSI prevalence was $38.4 \%$. However, it is higher when compared to teaching hospitals in India $(32.75 \%)$ and Nigeria (31.25\%) [13-15].

A Canadian study reported that the highest rate of injury was among dental students $(82 \%)$ followed by medical (57\%) and nursing students (27\%) [11]. In our study, however, the nursing students $(70 \%)$ had the highest rate of injury followed by medical interns $(20 \%)$ and dental interns $(10 \%)$. Since interns are mostly engaged in hands-on training, the injury rate could be higher in reality. This low rate, however, could be attributed to their low response rate. More than a half of them could not return questionnaires on time because they had busy schedules rotating in the teaching district hospitals at periphery.

High exposure rates to HIV (2.2\%) and HBV (4.4\%) positive cases in our study clearly highlight the vulnerability of health care workers including clinical trainees in Nepal. According to World Health Organization (WHO), annual proportion of health-care workers who get exposed to blood borne pathogens is $0.5 \%$ for HIV, $5.9 \%$ for $\mathrm{HBV}$ and $2.6 \%$ for $\mathrm{HCV}$ [6].

Regarding NSSIs, a majority of incidents occurred with Hollow bore needles. Manipulation of needle back and forth into an uncooperative patient was the main circumstance of injury. Our findings are supported by two studies, one done in Australia and the other done by Centers for Disease Control and Prevention in USA [16,17]. Trainees in our study usually had incidents in Internal Medicine ward as in Malaysia [7]. This could be because drawing venous blood sample from patient is the first procedure students get to learn in wards. Opening IV lines and suturing cut wounds are among other procedures which students seem to struggle with.

Although recapping the used needle has been discouraged and even prohibited by National Institute of Occupational Safety and Health (NIOSH, CDC) since 90's, around 3\% of NSSIs in US are still due to this practice [17]. Recapping led to $19 \%$ of injuries in our study. For many years, it has been a topic of debate especially in low income and technically poor countries like Nepal. Some health professionals argue that recapping may prevent the unexpected injuries both to the handler and to the people around him. Such myths need to be resolved soon and carrying out similar studies in a large scale might be a good initial step.

Regarding Post-exposure prophylaxis (PEP), only 11.1\% of those exposed took it either in the form of Tetanus toxoid or oral antibiotics. This lower rate could be attributed to low reporting tendency among students. A survey done by Perry J and Robinson S.R among nurses found that 15\% of exposed took PEP [18].
In our study, Hepatitis B vaccination status of the respondents was significantly associated with sociodemographic variables like faculty and gender and NSSI incident was significantly associated with faculty, age and gender. These findings are in accord with studies carried out by Shokier et.al in Kuwait [19].

The present study had some limitations. Though each respondent was assured of confidentiality, there was still a chance of bias in reporting, as the data were collected using self-administered questionnaires. Recall bias was another possibility. Some students might not have remembered the exact number of immunization doses they took during childhood. Regarding NSSIs, some trainees probably overlooked minor injuries while others reported about incidents that did not involve patient's blood. This study did not include all HCWs in the hospital (viz. Hospital assistants, Staff nurses, Residents and Staff physicians). The temporal association between variables could not be established as the study design was cross-sectional.

Nevertheless, several positive aspects of this study; one being it strength in raising occupational awareness in health institutions, could fairly overcome the limitations. The particular study could also be utilized as the resource first to carry out in-depth studies and then to formulate new health policies and regulations in Nepal.

\section{Conclusion}

The study revealed that a majority of students in the institute were vaccinated against Hepatitis B. However, as a matter of concern, those who were not vaccinated could be at higher risks of acquiring infections if they inflicted injuries with infected patients. Therefore, the health policy makers and executives must immediately address the common reasons that have been cited for non-vaccination.

Another alarming situation that needs to be tackled is high rate of NSSI among trainees, accompanied by a low tendency of Post-exposure prophylaxis and serology tests. A considerably high HIV and HBV exposure rates in the study calls for an extensive educational reinforcement on Universal precaution.

\section{Ethical clearance}

Institution Ethical Review Board, BP. Koirala Institute of Health Sciences, Dharan, Nepal.

\section{Competing interests}

All authors declare that they have no competing interest.

\section{Authors' contributions}

SB conceptualized the research, designed the proposal, developed the questionnaire, participated in data collection and prepared the manuscript for publication. PMSP, SKC, SL and SR helped conceptualize the research and revised the earlier drafts and corrected them before preparing a final report. SB and SKC were involved in data collection whereas SB and PMSP undertook data analysis. PMSP, SL and SR provided critical analysis to the earlier drafts of manuscript. All authors read the final version of manuscript for publication in scientific journal. 


\section{Authors' information}

SB is a Medical graduate from BPKIHS. He carried out this study during his Internship in 2012. He worked as a Medical Officer in Nepal for a couple of years and currently holds a position of Visiting Scholar in Cleveland Clinic Foundation, Ohio. He has interests in Infectious diseases, Injuries and Global health. SKC has been working as Program Associate in HIV \& SRHR Coalition Nepal and conducts trainings on HIV and STls to raise awareness among vulnerable groups. PMSP is Consultant Senior Public Health Officer in Influenza Surveillance Project at Patan Academy of Health Sciences (PAHS), Nepal. He is also a Lecturer at the Department of Community Health Sciences at PAHS. He received his Postgraduation degree in Community Medicine and Tropical Diseases from BPKIHS. $\mathrm{SL}$ is Professor and Head of Nursing education in BPKIHS. SR is Professor in the Department of Internal Medicine, BPKIHS and the Chief of Tropical and Infectious Disease Division. He is better known as the Scientist for his great contribution in the field of Infectious diseases in Nepal.

\section{Acknowledgement}

We acknowledge the medical, dental and nursing students along with the then interns who represented six batches (Batch 2006-2011) of BPKIHS. We are grateful to all the class representatives who helped us collect the data. We are very thankful to Prof. Prahlad Karki, Prof. Narendra Bhatta and Dr Surya Raj Niroula for their valuable ideas and suggestions.

\section{Author details}

${ }^{1}$ B.P. Koirala Institute of Health Sciences (BPKIHS), Dharan, Nepal. ${ }^{2}$ Ishan Children and Maternity Hospital, Kathmandu, Nepal. ${ }^{3}$ BPKIHS, HIV \& SRHR Coalition, Lalitpur, Nepal. ${ }^{4}$ Influenza Surveillance Project, Department of Community Health Sciences, Patan Academy of Health Sciences, Lalitpur, Nepal. ${ }^{5}$ School of Nursing, BPKIHS, Dharan, Nepal. Internal Medicine, Tropical and Infectious Diseases Division, BPKIHS, Dharan, Nepal.

Received: 19 February 2014 Accepted: 21 October 2014

Published: 3 November 2014

\section{References}

1. World Health Organization: Hepatitis B Fact sheet. [http://www.who.int/ mediacentre/factsheets/fs204/en/\#] [Internet].

2. World Health Organization: Global Alert and Response (GAR). [http://www. who.int/csr/disease/hepatitis/world_hepatitis_day/question_answer/en/] [Internet].

3. Nava Kiran Plus: Hepatitis: The Silent Scourge. [http://nkp.org.np/new/ contentdetail/news-and-events/99/hepatitis-the-silent-scourge.html] [Internet] [Accessed Oct 10, 2012].

4. World Health Organization: Global Immunization News. 2009. [PDF file Page 10] [http://www.who.int/immunization/GIN_May2009.pdf] [Internet] [Accessed Sept 30, 2014].

5. Federal Bureau of Prisons Clinical Practice Guidelines: Medical Management of Exposures: HIV, HBV, HCV, Human Bites, and Sexual Assaults. 2014 [PDF file Page 6 Table 2] [www.bop.gov/resources/pdfs/exposures.pdf] [Internet] [Accessed Nov 6, 2014].

6. Pruss-Ustun A, Rapiti E, Hutin Y: Sharps injuries: Global burden of disease from sharps injuries to health-care workers. 2003. [http://www.who.int/ quantifying_ehimpacts/publications/9241562463/en/] [Internet] [Accessed Nov 6, 2014].

7. Swe KMM, Zin T, Bhardwaj A, Abas ABL, Barua A: The Prevalence of Needle Sticks Injury among Medical Students in Melaka, Malaysia, A Cross Sectional Study. Eur J Sci Res 2012, 71(2):214-220.

8. Asif M, Raza W, Gorar ZA: Hepatitis B vaccination coverage in medical students at a medical college of Mirpurkhas. J Pak Med Assoc 2011, 61(7):680-682.

9. Nasir K, Khan KA, Kadri WM, Salim S, Tufail K, Sheikh HZ, Ali SA: Hepatitis B vaccination among health care workers and students of a medical college, Allama Iqbal Medical College, Lahore. J Pakistan Med Assoc 2000, 50(7):239-43.

10. Gurubacharya DL, KC M, Karki DB: Knowledge, attitude and practices among health care workers on needle-stick injuries. Kathmandu Univ Med J (KUMJ) 2003, 1(2):91-94.

11. McCarthy GM, Britton JE: A survey of final-year dental, medical and nursing students: Occupational injuries and infection control. J Can Dent Assoc 2000, 66:561.
12. Singh SP, Mishra GC, Mittal AK: Hepatitis B vaccination among medical, dental and nursing students at medical college of Orissa: Results of a survey. Indian J Gastroentero/ 2000, 19:33-34.

13. Kakizaki M, Ikeda N, Ali M, Enkhtuya B, Tsolmon M, Shibuya K, Kuroiwa C: Needlestick and sharps injuries among health care workers at public tertiary hospitals in an urban community in Mongolia. BMC Research Notes 2011, 4:184.

14. Singru A, Banerjee S: Occupational Exposure to Blood and Body Fluids among Health Care Workers in a Teaching Hospital in Mumbai, India. Indian J Community Med 2008, 33(1):26-30.

15. Akeem $\mathrm{OB}$, Abimbola $\mathrm{A}$, Idown $\mathrm{CA}$ : Needle stick injury pattern among health workers in primary health care facilities in Ilorin, Nigeria. Journal of SAVAP International 2011, 1(3):419-427.

16. Kermode M, Jolley D, Langkham B, Thomas MS, Crofts N: School of Population Health, University of Melbourne, Australia. Am J Infect Contr 2005, 33:34-41.

17. Centers for Disease Control and Prevention: The National Institute of Occupational Safety and Health (NIOSH): STOP STICKS CAMPAIGN. [http://www.cdc.gov/niosh/stopsticks/sharpsinjuries.html] [Internet] [Accessed Nov 6,2014].

18. Perry J, Robinson SE, Jagger J: Needle stick and sharps-safety survey. Nursing 2004, 34(4):41-47.

19. Shokier FN, Al-azami FS: Study of needle stick injuries among health care workers in Kuwait. Alexandria Bulletin 2006, 42(6):595-596.

doi:10.1186/1756-0500-7-774

Cite this article as: Bhattarai et al:: Hepatitis B vaccination status and Needle-stick and Sharps-related Injuries among medical school students in Nepal: a cross-sectional study. BMC Research Notes 2014 7:774.

\section{Submit your next manuscript to BioMed Central and take full advantage of:}

- Convenient online submission

- Thorough peer review

- No space constraints or color figure charges

- Immediate publication on acceptance

- Inclusion in PubMed, CAS, Scopus and Google Scholar

- Research which is freely available for redistribution

Submit your manuscript at www.biomedcentral.com/submit
C Biomed Central 